\title{
Study on Problems and Countermeasures of English Network Learning
}

\author{
Wenjie Zeng ${ }^{1}$, Shengqi Xiong ${ }^{2}$ \\ ${ }^{1}$ Minority Ethnic Preparatory College, Nanchang Institute of Science and Technology, Nanchang, \\ Jiangxi, 330108 \\ 346591653@163.com
}

KEYWORDS: Learning; English; Problems; Strategy

\begin{abstract}
Today is an era of globalization, the increasingly frequent international exchanges, English as a universal language, more and more attention, English has become an important tool of international communication. With the increase in the proportion of international economic and trade share in the national economy, people gradually realized the importance of English practicality, national education has done constantly adjusted according to the specific circumstances of the country to learn English, for example, in the preparation of English textbooks and digital publishing, English teaching methods and so on. English Online Learning Problems specifically set forth herein below and the Solution.
\end{abstract}

\section{The Problems in Network Learning}

With the upgrading of China's role in international economic and trade organizations, and international exchange has become increasingly frequent, many foreign companies have settled in the Chinese mainland, China gradually into the international community, but at the same time gave verbal communication has brought new people challenge the ability level of the English people put forward higher requirements. For now, the country has emerged as the overall level of spoken English is poor, using the wrong syntax, pronunciation, and so misnomer, write the quality of domestic English textbook is uneven, digital publishing segment also compared with respect to foreign difference; domestic English teaching methods are also serious problems. With the development of technology, the rapid development of the network for the convenience people's lives while contradictions have become increasingly prominent. Learning via the Internet in English, rich in resources, convenient, you can share resources, but because the network does not have the binding and the amount of information, more resources, lack of easy to learn direction.

\section{A. There is no Standard English Textbooks in English Learning}

Preparation and publication of textbooks are based on groups of objects for teaching materials and positioned to extend content. In the actual teaching process, textbooks are written in English according to the use of objects and materials groups targeted, the characteristics and needs of this specific target groups to prepare teaching materials, rather than generalities. But in the network learning environment is the lack of standard English textbook guide, although the network can search a lot of English learning materials but many textbook content is not standardized, and this is great for beginners English problems, and even lead to beginners learning English come to a dead end. 


\section{B. The Network Some English Learning Content Obsolete}

English is mainly reflected in the value of its foreign economic and trade, it requires practical. Social is development rapidly, the advancement of technology, especially computer technology and Internet technology, which is an important sign of the times. Network technology has become more sophisticated, so that e-books instead of the original heavy textbooks books, simple and convenient, update speed, but the problem is associated with the fore. Network update quickly, but in the past some old English learning content still exists in the network, there is no cut, for starters, the lack of English learning judgment, likely to collect all the English learning content obsolete, which is extremely unfavorable for learning English; in addition to the same grammar explanation, may the new English learning content and the old version of the English learning content differ, this is a problem for beginners, there is no uniform easily lead to learning grammar explanations deviation.

\section{The Network Learning English Teaching Materials Supporting Incomplete}

English learning content covers a wide range must, in order to meet the needs and changes in the social and national development. Complete English learning content include: basic English words and grammar; supporting training; teaching video courseware; Spoken English training; English listening training; English textbooks extension, etc., rich network resources, large amount of information and complex, but if you are looking for a complete English learning materials is difficult, piecemeal, assorted mixed.

\section{English Learning Content and Learning Methods Has Limitations}

English has involved a wide range of professional, practical requirements and so on. Learning environment because the teacher to explain the lack of face to face, it is not conducive to the extension of English learners to learn English, it limits the range of English learning content. Learning is a network environment, mixed, network textbook learning English and some only for the content of business English one aspects of the preparation, content-rich enough, and less to explain the point surface, which for a English beginners is extremely inappropriate, based tutorial is not perfect beginning for the future of English learning planted dangerous and not conducive to divergent learner thinking.

\section{How to Solve the English Online Learning Problems}

\section{A. The Standard of English Teaching Materials to Share Network, Share Resources, Learning}

In the actual teaching of English, the English teaching is based on the materials, plus the teacher's explanation and analysis, students can better understand and learn English course. So it is the basic teaching materials. Actual teaching, before writing English teaching materials, must first write business English this material objects clearly, not generalities, there is no targeted. To clear objects Business English textbook compilation, it must be based on education research, write this out of English teaching materials to meet students' practical, to achieve good learning results. But the network environment can not compare the actual teaching environment, which is also part of the network environment lacking. Electronic versions of the actual teaching of English textbooks written finalized can be uploaded to the learning environment, such as a network standard English learners of English learning materials, but also can be domestic and international network of English textbooks gathered together, comparing each other, more conducive to learning English.

\section{B. The English Learning Process Must have A Scientific Theory as A Guide}

From many years of education and teaching is not difficult to see that English has a comprehensive discipline is not only a manifestation of language skills and knowledge, but also a 
test of personal expertise. In practical English teaching, students learning English for teachers as a guide, how to learn, to learn where to start, how to use the materials and so on, have done teacher guidance, while the teacher with years of teaching experience, students learn English control has matured, but also often between teachers teaching seminars, the purpose is the exchange of teaching experience, learn from each other and improve their English teachers teaching. However, in a network environment, English learners are individuals in the effort not the teacher's face guidance, no extra people can communicate, there is no doubt who is an individual to answer, so the learning process is extremely easy on the direction of the deviation, the individual delay English learning. So learning English must have a scientific theory as a guide. There was a scholar said, to strengthen the theory is the fundamental way to continue the development of English subjects, we can see that in the process of learning English as a theoretical knowledge of the importance of scientific guidance, especially in the network environment. Personal Learning Network is a bearer of knowledge of English, how to make better use of network learners this carrier to learn English, we must strengthen the network of the carrier construction. The construction of the network carry needs the help of scientific theoretical knowledge and insightful theory. On English learning, the theory needs to cross disciplines, ie language skills and knowledge and expertise between the cross integration. Cross theoretical knowledge to help guide the process of individual learning English to help English learners improve their English quickly, contributing to the social culture of the English compound talents.

\section{Several Aspects of the English Learning Content Need to Improve}

(1) In the process of learning English should pay attention to English learning content must be realistic problems, and content with the real meaning

Complete English learning content include: basic English teaching; supporting the practice; teaching video courseware; Spoken English training; English listening training; English textbooks and so extend, hearing English listening training material and some news from the community, some from the International dynamic, some knowledge from literature, etc., on the coverage of the listening material is necessary to consider the practicality, listening material and teaching materials bonded phase, but also require the authenticity of listening material, if it is false, that would mislead the learner English understanding.

(2) Focus on learning English in the process of learning English content comprehensive, informative, and gradually increase the difficulty, can not be done overnight. One of the biggest feature is the free network environment of learning, can choose their favorite learning content, but precisely because of this led to a lot of English for beginners Want to ignore comprehensive English learning content too unitary. Today is an era of comprehensive development, so upgrading knowledge must also keep pace with the times, for the English-learning must also keep pace with the times, in the network learning environment, English learning content must cover all aspects of social development, which is conducive to learners, help society to cultivate talent all-around development. And English is the international aspect of the overall development in the ongoing domestic to follow the international pace to do with the times.

(3) In the process of learning English, learning English content needs to sift, English learning content need to be flexible, innovative.

A learning method is that the people most deeply rote, which is China's largest education problems, a lot of people in the process of learning English is also used in this way, and that language learning as just memorize it, but wrong, doing so results are poles apart. And rote learning

more English that does not apply to network learning environment. For the content of learning English can not die move rigidly applied in the past with reference to the practice of learning to be 
selective and flexible use, such as today's society and the dynamic development of international news, etc. is an important part of learning English, so you can extend learners thinking more and vision; for spoken English and grammar training can use more multimedia and other network technology.

\section{REFERENCE:}

[1] Hu Changen. College Students Online English Learning Strategies and Countermeasures [D]. Shanghai International Studies University, 2007.

[2] Zhu Ye. English Online Learning Strategies and Problems and Countermeasures [J]. Foreign Language Education, 2005,01: 23-26.

[3] Luo Yuhui, Han Li. Problems and countermeasures when Cultivating the Independent Learning Ability under the network environment [J]. China Education Innovation Herald, 2012,31: 136-137.

[4] Zhang Jialiang. Public College Students Learning English Online Courses Investigation and Countermeasures [D]. Yunnan University, 2013.

[5] Liao Shuna. College English Autonomous Learning Problems and Solutions [J]. Luliang College of Education, 2014,02: 83-85. 